of their growth and decline, of a method of determining their depth below water, and of the probability of specialized life existing beneath such formations.

The President expressed to Sir Douglas Mawson the thanks of the Fellows and visitors for his lecture.

\title{
II.-Mineralogical Sochety.
}

June 18, 1918.-W. Barlow, F.R.S., President, in the Chair.

W. A. Richardson: "On the Origin of Septarian Nodules." Septarian structure consists not of a simple combination of radial and concentric circles, but of irregular polygons closely simulating mud-cracking. By experiments with clay balls and films and comparison with timber cracks it was shown that radial cracks widening inwards are produced by internal circumferential contraction, radial cracks widening outwards by internal expansion, concentric cracks by contraction towards the centre, and polygonal cracks by either free or chemical desiccation. Moreorer, analysis shows that septarian nodules are more aluminous towards the centre than the outside, and are therefore capable of contraction. The evidence disproved the expansion theories, and showed that contraction on numerons centres in a colloidal medium caused the cracking, and desiccation by chemical agents the contraction. The central portions are not merely enclosed clay, but clay that has undergone considerable chemical modification, and the original colloidal nature of the medium is so changed that closing of the cracks by absorption when placed in water cannot take place. Finally, the occurrence of the nodules suggests their origination by rhythmic precipitation according to the laws of liesegang from solutions of bicarbonates diffusing through a colloidal medium.

Dr. G. T. Prior: "The Composition of the Nickeliferous Iron of the Meteorites of Powder Mill Creek, Lodran, and Holbrook." A simple and expeditious method of determining the amount and chemical composition of the nickeliferous iron of a meteorite was described. The method depends upon the use of dimethyl glyoxime for the separation of nickel. Its application to the meteorites of Powder Mill Creek, Lodran, and Holbrook gave percentages respectively of about 42,30 , and $6 \frac{1}{2}$ of nickeliferous iron, in which the corresponding ratios of iron to nickel were about $13,11 \frac{1}{2}$, and 5 .

\section{OOREESPONDEROE.}

MOUNTAIN BUILDING.

Sir,-The aim of my article in the Geological Magazine for May was to point out that those data for the earth's thermal condition and past history that agree best with evidence derired from totally different sources lead directly to an amount of compression of the earth's crust in cooling that is of the correct order of magnitude to account for mountain building. $\mathrm{Mr}$. Deeley in his reply makes no attempt to answer this statement. What he does is to suggest that 
different data, less satisfactory on other grounds, might lead also to a less satisfactory amount of contraction or even to an expansion. This is an argument in farour of the data and of the theory, and not against them.

His assertion that I would have readers "believe that the thickness of the radio-actire layer has been fairly accurately measured", and his charge of "dogmatism", are definitely untrue. It was because it is not accurately known that I determined the available compression on two hypothetical distributions of radio-active matter, both permissible on other grounds, but widely different; the results they gave were not very different and were stated in the article.

I introduced no new theories regarding the properties of matter. What $I$ did was to classify in a convenient way the known behaviour of different types of matter under shearing stress. The statement quoted from Maxwell that liquids and perhaps most solids are perfectly elastic as regards stress uniform in all directions is irrelerant to my discussion, which was explicitly limited to the differences between the stresses in different directions. In the light of present knowledge the account of shearing stress in Maxwell's book needs revision; for it makes no reference to elastic after-working or to the elasticity of such a substance as pitch, which in $\mathrm{my}$ classification would be a plastic solid with a rery low limiting stress-difference. 'The common practice of regarding as a liquid a substance so elastic that tuning forks can be made of it is exceedingly inconvenient.

Had the conclusion, that my views on the solid and liquid states are quite inadmissible, been accompanied by the slightest argument, it might have been more impressive; or it might not.

HAROLD JEFFRYS.

\section{THE PRE-THANETIAN EROSION OF THE CHALK.}

Srr,-I have read with much interest the suggestive paper by Mr. H. A. Baker on the "Pre-Thanetian Erosion of the Chalk in the London Basin". I have for some time past been accumulating evidence for a similar study, but in 1915 wrote that "the evidence ... is as set too slight to allow of a definite map being made" (Geology of Windsor and Chertsey, Mem. Geol. Surv., p. 14).

Mr. Baker's map (Fig. 1) includes the area to which I referred, and appears to be based upon less evidence than that which my work for the Geological Surrey had afforded. In the construction of such a map it seems natural to ascertain as far as possible the zone of the Chalk immediately underlying the Tertiary at the boundary of the latter, and to check the zones whose presence beneath the Tertiary is deduced from borings by these facts. This has not been done by Mr. Baker. The zone of Chalk on which the Tertiary rests has been ascertained by the Survey in the south-western part of the area shown on Mr. Baker's map, and a portion of the results has already been published (op. cit.). From the neighbourhood of Beaconsfield to the western margin of the map forming Fig. 1 he shows the base of the Tertiary as resting on the zone of $A$. quadratus. The fact is, that the zone is that of $\boldsymbol{M}$. cor-anguinum at Beaconsfield, Marsupites 